\title{
Pathology of cardiomyopathy from South India
}

\author{
C. R. R. M. Reddy, G. Parvathi, and N. Ramachandra Rao \\ From the Department of Pathology and the Department of Medicine, Kurnool Medical College, \\ Kurnool (Andhra Pradesh), South India
}

Seven cases of cardiomyopathy are presented with detailed macroscopical and microscopical studies. There are some differences and also similarities between this group and those described by Davies from Uganda. Myocytolysis was present in all cases, and appeared earlier than endocarditis. The earliest endocardial lesion was smooth muscle hyperplasia. Feeding of monkeys with plantains for more than 8 months failed to produce any changes in the heart.

After Bedford and Konstam (1946) described dilatation of the heart with subendocardial fibrosis and mural thrombosis (the latter being an inconstant feature) there were numerous reports relating to cardiac failure due to cardiomyopathies of unknown aetiology. Under differing nomenclature, various authors described obscure heart diseases from all over the world - Davies (I948) from Uganda, Gillanders (I95I) and Becker, Chatgidakis, and van Lingen (1953) from South Africa, Edington and Jackson (1963) from Nigeria, and Hill, Still, and McKinney (1967) from Jamaica, O'Brien (1954) from Sudan, Nagaratnam and Dissanayake (1959) from Ceylon, and Andrade and Guimarães (1964) from Brazil. From India the necropsy reports on cardiomyopathy were reviewed by Reddy, Murthy, and Rao (1969). The World Health Organization has conducted three International Meetings to elucidate the problem of cardiomyopathies and published them in the Bulletin of the World Health Organization in 1965 and 1968 and in the Chronicle of the World Health Organization in 1967. At these meetings, mention was made of the common incidence of endomyocardial fibrosis in Kerala State in the lower West coast of South India, and that idiopathic cardiomegaly (a name suggested for all the other types of cardiomyopathies apart from endomyocardial fibrosis in the Kingston Conference of W.H.O. (1967)) was quite often seen in the Delhi area. The present report is a study of seven necropsy reports from the Deccan Plateau of South India.

\section{Material and methods}

In 2010 necropsies (excluding stillbirths) between August 1960 and June 1969, there were 220

Received 30 July 1969. deaths due to cardiovascular disease: these were analysed according to aetiology. In addition, analysis was made of 120 cases of cardiovascular disease encountered in 13 months by one physician, out of ror2 admissions to his ward.

Seven cases of cardiomyopathy encountered at necropsy were studied in detail both macroscopically and microscopically. Sections for histopathology were taken from the mitral valve ring including a bit of the left ventricle, left atrium, and mitral valve cusp; the apex of the left ventricle including the pericardium and endocardium; the anterior papillary muscle; the right atrium; the aortic outflow path; the apex of the right ventricle; the left atrial appendage; the right atrial appendage; the pulmonary outflow tract; the pulmonary artery; the uninvolved (endocardium) portion of the muscle of the septum; and the anterior descending branch of coronary artery.

Serial sections were stained with haematoxylin and eosin, Masson's trichrome, Wilder's reticulin, PAS, toluidine blue, Alcian blue, Perls' stain for iron, and Verhoeff-van Gieson stains.

Six monkeys were studied for the effect of plantain diet on the heart. Two were kept as controls. Four were given only plantains (locally available green and yellow varieties) for 8 months. All the 6 monkeys were brought to necropsy at the end of 8 months and the hearts were studied in the same way as the human hearts.

TABLE I Heart weights (normal)

\begin{tabular}{lrlllllll}
\hline $\begin{array}{l}\text { Age-group } \\
(y r .)\end{array}$ & \multicolumn{4}{c}{ Male patients } & \multicolumn{3}{c}{ Female patients } \\
\cline { 2 - 9 } & No. & $\begin{array}{l}\text { Mean } \\
(g .)\end{array}$ & $S D$ & $\begin{array}{l}\text { Range } \\
(g .)\end{array}$ & No. & $\begin{array}{c}\text { Mean } \\
(g .)\end{array}$ & $S D$ & $\begin{array}{c}\text { Range } \\
(\mathrm{g} .)\end{array}$ \\
\hline $11-20$ & 47 & 162 & 49 & $80-305$ & 70 & 152 & 38 & $60-275$ \\
$21-30$ & 95 & 188 & 34 & $115-235$ & 116 & 180 & 38 & $110-300$ \\
$31-40$ & 121 & 194 & 39 & $110-285$ & 53 & 183 & 43 & $110-300$ \\
$41-50$ & 108 & 196 & 45 & $115-345$ & 41 & 187 & 46 & $100-290$ \\
$51-60$ & 43 & 206 & 43 & $135-300$ & 21 & 198 & 49 & $160-290$ \\
\hline
\end{tabular}


In 7 I5 necropsies where there was neither clinical nor macroscopical nor microscopical changes in the heart, the heart weights were analysed to find the normal weights of heart for different ages in either sex and are given in Table $I$.

The maximum heart weight in men was $345 \mathrm{~g}$. in the age-group $4 \mathrm{I}-50$, and in women $300 \mathrm{~g}$. in the age-group $3 \mathrm{I}-40$. From the Table it is seen that on an average in men the weight increased from $210 \mathrm{~g}$. between II and 20 age-group to $250 \mathrm{~g}$. between 51 and 60 age-group. In women the average weight increased from $190 \mathrm{~g}$. in the I to 20 age-group to $247 \mathrm{~g}$. in the $51-60$ age-group.

Weights above $350 \mathrm{~g}$. in men and $300 \mathrm{~g}$. in women were taken as cardiomegaly.

\section{Results}

Table 2 analyses the 120 clinical and 220 necropsy cases according to aetiology.

Heart diseases formed $\mathrm{II} \cdot 8$ per cent (120/IOI2) of the clinical admissions and 10.9 per cent (220/2010) of the necropsies.

Cardiomyopathies comprised 12.5 per cent of clinical admissions and 3.2 per cent of the necropsies on heart diseases.

The seven cases of cardiomyopathy seen at necropsy consisted of 5 men of 20,20 , 35,43 , and 45 years, respectively, and 2 women of 30 and 35 years, respectively. All of them were admitted for congestive heart failure, and in one of them a pericardial effusion was diagnosed clinically. Most of these cases came in the terminal stages except Cases I and 5 (see Table 3) which were repeatedly admitted for congestive heart failure to the hospital.
TABLE 2 Analysis of clinical and necropsy cardiac diseases according to aetiology

\begin{tabular}{|c|c|c|c|c|}
\hline Aetiological factors & $\begin{array}{l}\text { Clinical } \\
\text { series }\end{array}$ & $\begin{array}{l}\text { Per } \\
\text { cent }\end{array}$ & $\begin{array}{l}\text { Necropsy } \\
\text { series }\end{array}$ & $\begin{array}{l}\text { Per } \\
\text { cent }\end{array}$ \\
\hline $\begin{array}{l}\text { Rheumatic heart } \\
\text { disease } \\
\text { Hypertensive heart }\end{array}$ & 32 & $26 \cdot 7$ & 62 & 28.2 \\
\hline $\begin{array}{l}\text { disease } \\
\text { Ischaemic heart }\end{array}$ & 25 & 20.9 & 55 & $25 \cdot 0$ \\
\hline disease & 25 & $20 \cdot 9$ & 19 & $8 \cdot 6$ \\
\hline $\begin{array}{l}\text { Cor pulmonale } \\
\text { Congenital heart }\end{array}$ & 18 & $15 \cdot 0$ & 25 & II 4 \\
\hline disease & 5 & $4 \cdot 2$ & 23 & 10.5 \\
\hline Myocarditis & - & - & 29 & $13 \cdot 2$ \\
\hline Cardiomyopathy & 15 & $12 \cdot 5$ & 7 & $3 \cdot 2$ \\
\hline Total & 120 & & 220 & \\
\hline
\end{tabular}

Table 3 gives the main macroscopical features of the heart and other organs in the seven necropsies. It is seen that all the hearts are bigger than normal except for Cases 3 and 5. In Case 6, there was pericardial effusion. In all the cases there was endocardial thickening in the left ventricle, ranging from I to $5 \mathrm{~mm}$. This was usually seen near the apex and extended along the inflow and outflow tracts, but in no case did it involve the aortic valve. Endocarditis in Cases 4, 5, and 6 was diffuse in the left ventricle (Fig. I). In Case 7 there were only a few patches of endocarditis here and there. In Case 3 it was typical of endomyocardial fibrosis. In Cases $I$ and 2 it was thick and covered with exten-

TABLE 3 Main necropsy findings

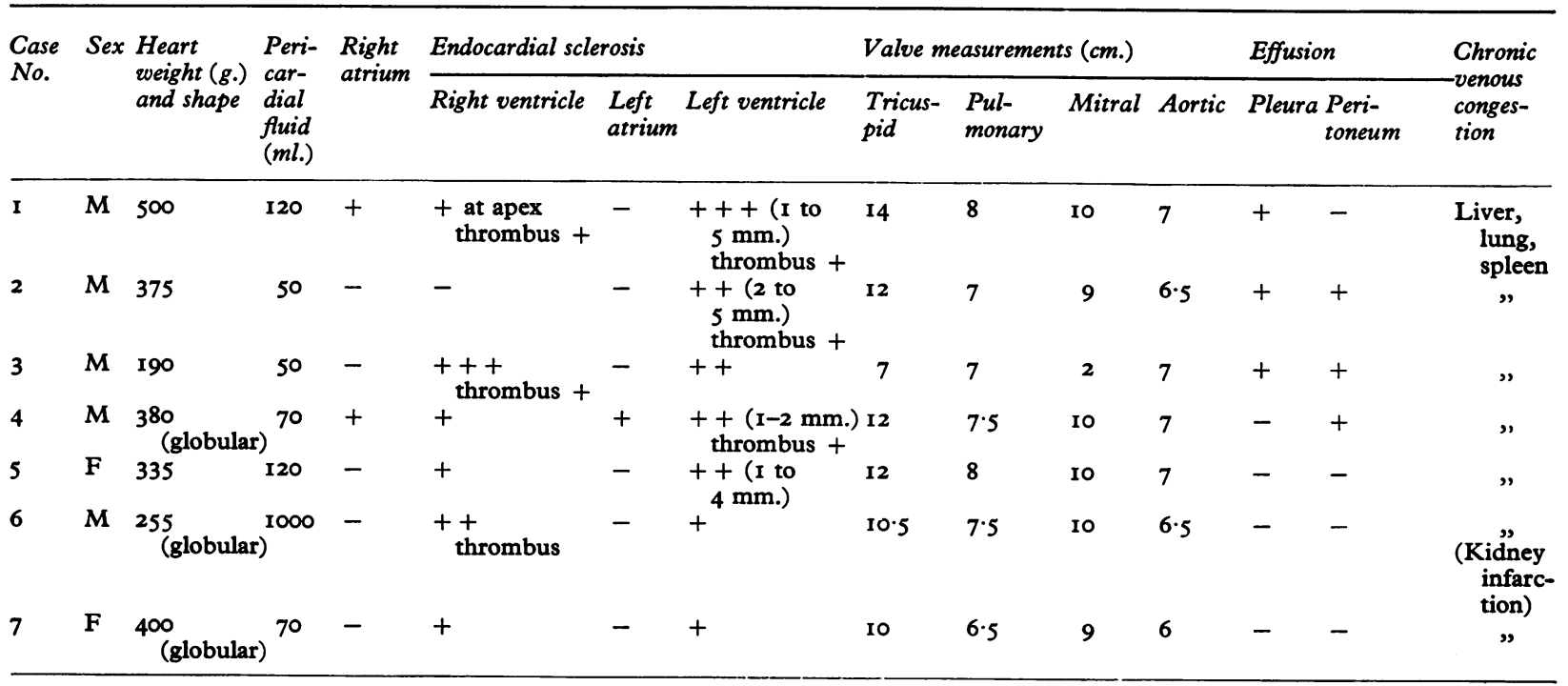


sive adherent thrombosis (Fig. Ib). Except for Case 2, right ventricular endocardium showed endocarditis and in one case it extended up to the pulmonary valve and stopped short in the form of a rolled edge. The right atrium in Cases $I$ and 4 and the left atrium in Case 4 showed a few patches of endocardial thickening. The shape of the heart was globular in Cases 4, 6, and 7. In Case 3 it resembled the typical external appearance of endomyocardial fibrosis with a depressed scar on the right border above the apex (Fig. IC and d). Apart from Case 3, all the valves were normal. In Case 3 the posterior mitral valve leaflet was completely incorporated in the endocardium as was the tricuspid valve by the endocardial sclerosis extending upwards along the inflow tracts from the apex in both ventricles. The right ventricular cavity was narrowed down to a volume of $5 \mathrm{ml}$. by the endocardial sclerosis. The three hearts which showed a globular shape showed also the conversion of the trabeculae into a lace-like pattern and patchy endocarditis. Adherent antemortem mural thrombus was present in five cases, in the right ventricle alone in 2 cases, in the left ventricle alone in 2 cases, and in both ventricles in I case. But no embolic phenomena were seen elsewhere except in one case in the kidney. Pleural effusion in one and ascites in one and both pleural and peritoneal

FIG. I (a) Opened out left ventricle of Case 4 with left ventricular endocardial sclerosis.

(b) Opened out left ventricle of Case I with extensive mural thrombosis and endocardial sclerosis.

(c) Right, the external surface of heart (Case 3) showing depressed scar about $2 \mathrm{~cm}$. above the apex; left, the enlarged left atrium and the small left ventricle below with the secured mitral leaflet. (d) Right, the opened right ventricle (Case 3), with the endocardial ridge; left, the opened left ventricle, showing the absence of endocardial sclerosis along the outflow tract.

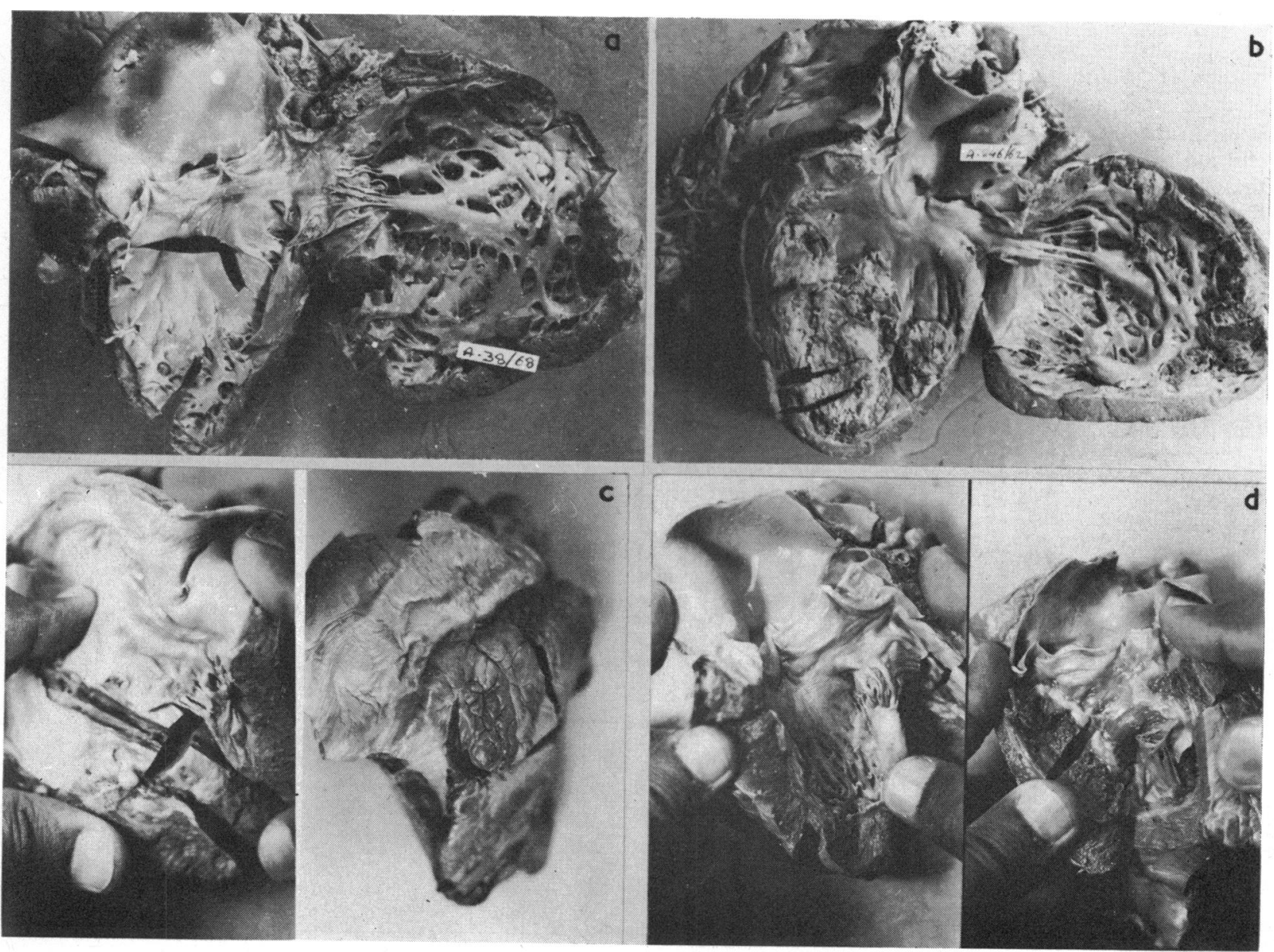


effusions in two cases were observed. Chronic venous congestion of all the viscera was present in all cases.

In Case 5, there were two small $\left(\frac{1}{2} \mathrm{~cm}\right.$. in diameter) patches of endocardial thickening which were glistening and oedematous. Histological study was made of the earliest changes in the endocardium.

Histopathology The myocardium showed extensive damage. Damage to the myocardial fibres was in the form of complete lysis, ring shapes, moth-eaten appearance, vacuolation, vacuolation of the nuclei of the myofibres, loss of striation in areas, and swelling of the muscle fibre (Fig. 2a). But the most constant change seen was myocytolysis (Fig. 2b). There was no cellular infiltration into these areas of myocytolysis. These areas of muscle damage were haphazardly present but more often than not they were present towards the endocardium and not the pericardium. There was no relation between the endocardial changes and the myocardial changes. In areas of myocytolysis and resultant fibrosis there was PAS-positive pigment. In some of the hearts the areas of myocytolysis were quite extensive. Maximum amount of myo- cytolysis was seen where the muscle mass was maximum. In all the seven hearts examined, in the left ventricle near the apex, the papillary muscles, the septum, and the right ventricular apex, myocytolysis of varying grades of intensity was present. In five of the hearts there were a few areas of myocytolysis in the right atrium also. In only one case was there myocytolysis in the left atrial muscle. Around the areas of myofibril damage, beneath the endocardium and in other areas haphazardly distributed there was hyperplasia of myocardial fibres. In these hypertrophied fibres and also in other areas there were bizarre nuclei in the muscle fibres with odd shapes. The nature of these nuclear changes could not be ascertained.

Myocytolysis was present also in Cases 3 and 5, particularly Case 3, which is typical of endomyocardial fibrosis as described by Davies from Uganda. Myocytolysis was seen quite extensively in Case 7 where the endocardial lesions were yet to develop fully and were only minimal at the time of necropsy.

\section{Changes in endocardium}

Microscopically the maximum amount of change in the endocardium was seen in the

FI G. 2 (a) Photomicrograph of the heart showing myocytolysis. (Masson's trichrome. $\times 60$.)

(b) Photomicrograph of the heart showing myocytolysis without cellular infiltration.

(Masson's trichrome. $\times 20$.) (c) Photomicrograph of endocardium showing adherent organized thrombus on top of the normal endocardium with the normal elastic fibres. (Verhoeff's van Gieson. $\times$ 60.)

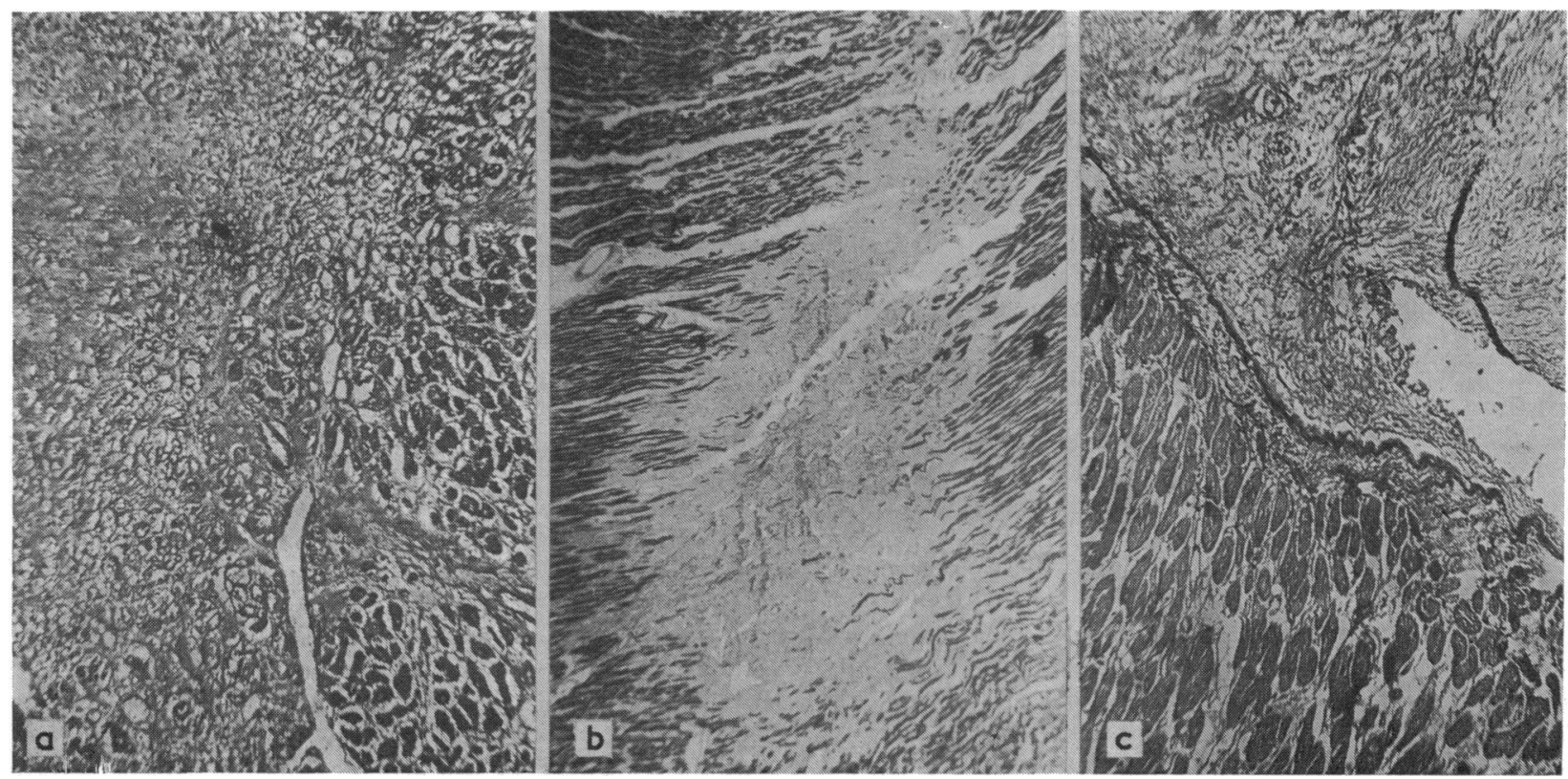


left and to a certain extent in the right ventricles. The earliest change which we could see was a focus of smooth muscle hyperplasia on top of the normal endocardial elastic membrane. There was smooth muscle hyperplasia together with metachromatic ground substance between the muscle fibres. There was no reduplication of the elastic tissue. Such foci of smooth muscle hyperplasia were present elsewhere also in the endocardial sclerosis. The tissues involved in the thickening of the endocardium are smooth muscle cells, elastic tissue, and fibrous tissue as a result of organization of adherent thrombus (Fig. 2c). These changes were haphazardly distributed. The endocardial changes enveloped the trabeculae and even obliterated them. Reduplication of elastic tissue and smooth muscle cell hyperplasia might be present on one side of the trabeculae and not on the other side, showing the inconsistency and irregularity. The change was also of varying thickness. The adherent organizing thrombus added to the thickness of the endocardial changes as evidenced by the presence of stainable iron in the thickened endocardium. Where the endocardial thickening stopped in the form of a rolled edge (as in Case 3) there was no specific histological change at the junction of normal and abnormal endocardium. In some areas, the endocardial sclerosis extended downwards into the myocardium in the form of tonguelike extensions. Only smaller arteries and arterioles showed changes. No changes could be seen in the main coronary arteries or their branches. The changes were in the form of thickening of the intima and also, in some, occlusion by thrombi. But these changes appeared to be more recent and had no relation at all to the myocytolysis or endocarditis. The changes appeared to be due to endocardial sclerosis as the blood vessels were usually beneath the endocardium.

In the monkey hearts, studied both macroscopically and microscopically, at the end of an eight-month period no change could be seen. There was no change in the endocardium in any of the chambers nor in the muscle fibres. There was no necrosis, myocytolysis on fibrosis, or any of the other changes described in the human hearts.

\section{Discussion}

The first three cases of the present series were included in the review of seven cases by Reddy et al. (1969) from Kurnool. Rao et al. (1969) reported Case 4 of the present series as a clinicopathological study. In the seven cases reported, only Reddy et al. (1965) described myocytolysis. Mehrotra et al. (1964) reported degeneration of the myocardium. Kinare and Deshpande (1965) reported interstitial fibrosis and atrophy of the myocardium in the vicinity of the endocarditis. Samuel and Anklesaria (1960) also reported only myocardial degeneration. In all seven cases in the present series myocytolysis was a prominent feature. Definite examples of endomyocardial fibrosis have been reported from Ceylon (Nagaratnam and Dissanayake, 1959).

The cardiomyopathy occurring in South India as described above differs to a certain extent from what is classically described from Uganda by Davies (1960), in that the hearts weighed more, and typical valvular involvement occurred in only one case. Endocardial lesions were diffusely present in all cases except in one in which it resembled the description of Davies. But myocytolysis was present in all the cases, a lesion essential to the diagnosis of endomyocardial fibrosis (Hill et al., 1967). It is difficult to say whether the hearts described by us are similar to those described in Uganda as endomyocardial fibrosis: the variations may be a matter of degree.

Edington and Jackson (1963), in an exhaustive study of hearts with cardiomyopathy from Nigeria, reported that myocardial damage in the form of myocytolysis and degeneration was the earliest change seen in the enlarged hearts. Later there might be visible fibrosis of trabeculae carneae; and adherent mural thrombi might form on this altered endocardium, become organized, and more thickening of endocardium would result, with sclerosis. The sclerosis might involve the chordae tendineae and papillary muscles and valve leaflets. Thus they put forth a unitary concept to explain the various types of heart disease described from Africa, and considered that endomyocardial fibrosis and cardiomegaly of unknown origin had similar pathological changes. However, Parry and Abrahams (1965) do not agree with this. The World Health Organization Conference on idiopathic cardiomegaly also came to the conclusion that endomyocardial fibrosis and idiopathic cardiomegaly were distinct entities but that myocytolysis also might be present in idiopathic cardiomegaly (World Health Organization, I968, p. 988), with resultant fibrosis. Shaper (1967) also considered that endomyocardial fibrosis and idiopathic cardiomegaly were two distinct entities.

Attention has now focused on the role of 
smooth muscle, and Wissler (1967) writing an editorial in Circulation mentioned that the smooth muscle of arteries was a multifunctional mesenchyme and that this cell could even migrate and take part in the fabrication of elastic fibres, mucopolysaccharides, and myosin. In the earliest lesions in the endocardium, the smooth muscle hyperplasia with metachromatic ground substance around the muscle fibres indicates the importance of the smooth muscle in the causation of endocardial thickening and elastosis. This is distinct from the endocardial thickening caused by the organization of adherent thrombus.

The relation between plantain diets, serotonin, and endomyocardial fibrosis has been studied by several workers. McKinney and Crawford (1965) produced endocardial lesions in guinea-pigs on plantain diets. The role of chronic lymphatic obstruction was studied in dogs fed on plantains and controls, but no endomyocardial fibrosis developed (Antia, Talbert, and Paplanus, 1966). Our studies on monkeys fed with plantains did not show any change in the myocardium or endocardium.

The cardiomyopathy seen by us here appears to be primarily a myocardial rather than an endocardial lesion. The endocardial lesion appears to be secondary to the myocardial lesion. The left ventricle has constrictor muscles and spiral muscles, the former to reduce the cavity and the latter helping to empty the ventricle (Goodwin, 1968). If there is extensive myocytolysis occurring irregularly in the ventricular, papillary, and septal musculature, the resulting improper contraction of the musculature could set up tension on the endocardium either at the site of muscle damage or away from the area because of the irregular way the muscle fibres are distributed in the heart. The tension spots on the endocardium may set up a smooth muscle hyperplasia in the beginning. This is so probably because myocytolysis is an earlier change than endocardial sclerosis, as seen in Case 7. These may become sclerosed, or elastic tissue reduplication may occur in these areas as smooth muscle is believed to be a multifunctional mesenchyme (Wissler, 1967).

\section{References}

Andrade, Z. A., and Guimarães, A. C. (1964). Endomyocardial fibrosis in Bahia, Brazil. British Heart Fournal, 26, 813.

Antia, A. U., Talbert, J. L., and Paplanus, S. (1966) 5th World Congress of Cardiology, New Delhi. Abstracts, p. 7. (Quoted by Shaper, 1967.)
Becker, B. J. P., Chatgidakis, C. B., and van Lingen, B. (1953). Cardiovascular collagenosis with parietal endocardial thrombosis: a clinicopathologic study of 40 cases. Circulation, 7, 345 .

Bedford, D. E., and Konstam, G. L. S. (1946). Heart failure of unknown aetiology in Africans. In Proceedings of the Cardiac Society of Great Britain and Ireland. British Heart fournal, 8, 236.

Davies, J. N. P. (1948). Pathology of Central African natives. Mulago hospital post mortem studies. IX. Cardiovascular diseases. East African Medical fournal, $25,454$.

(1960). Some considerations regarding obscure diseases affecting the mural endocardium. American Heart fournal, 59, 600.

Edington, G. M., and Jackson, J. G. (1963). The pathology of heart muscle disease and endomyocardial fibrosis in Nigeria. Fournal of Pathology and Bacteriology, 86, 333.

Gillanders, A. D. (I95I). Nutritional heart disease. British Heart fournal, $13,177$.

Goodwin, J. F. (1968). Acquired non-rheumatic mitral disease. Fournal of the Royal College of Physicians of London, 3, 6r.

Hill, K. R., Still, W. J. S., and McKinney, B. (1967). Jamaican cardiomyopathy. British Heart fournal, 29, 594 .

Kinare, S. G., and Deshpande, D. H. (1965). Endomyocardial fibrosis. Report of 2 cases. Indian fournal of Medical Sciences, 19, 63.

McKinney, B., and Crawford, M. A. (1965). Fibrosis in guineapig heart produced by plantain diet. Lancet, 2, 880.

Mehrotra, A. N., Maheshwari, H. B., Khosla, S. N., and Kumar, S. (1964). Endomyocardial fibrosis (a report of two cases in brothers). Fournal of the Association of Physicians of India, 12, 845.

Nagaratnam, N., and Dissanayake, R. V. P. (1959). Endomyocardial fibrosis in the Ceylonese. British Heart fournal, 21, 167.

O'Brien, W. (1954). Endocardial fibrosis in the Sudan. British Medical fournal, 2, 899.

Parry, E. H. O., and Abrahams, D. G. (1965). The natural history of endomyocardial fibrosis. Quarterly fournal of Medicine, 34, 383.

Rao, N. R., Reddy, C. R. R. M., Chetty, P. S., Moorthy, D. E. K., Ramasubbaiah, Y., and Suvarnakumari, G. (1969). Endomyocardial fibrosis (clinicopathological study of a case). Fournal of the Association of Physicians of India, 17, 51 .

Reddy, C. R. R. M., Murthy, V. S. N., and Rao, A. N. R. (1969). Endomyocardial fibrosis. fournal of the Indian Medical Association, 53, 17.

Reddy, D. J., Omer, S., Prabhakar, V., Rao, P. S. S., and Rao, K. S. (1965). Endomyocardial fibrosis. fournal of the Indian Medical Association, 45, 440.

Samuel, I., and Anklesaria, X. J. (I960). Endomyocardial fibrosis in South India. Indian fournal of Pathology and Bacteriology, 3, I 57.

Shaper, A. G. (1967). On the nature of some tropical cardiomyopathies. Transactions of the Royal Society of Tropical Medicine and Hygiene, 6r, 458.

Wissler, R. W. (1967). The arterial medial cell, smooth muscle, or multi-functional mesenchyme. Circulation, 36, $\mathrm{r}$.

World Health Organization (I965). Cardiomyopathies. Drafted by Hutt, M. S. R., Ikeme, A. C., Lucas, A. O., Prata, A., Puigbo, J. J., Shaper, A. G., and Fejfar, Z. Bulletin of the World Health Organization, 33, 257.

- (1967). The cardiomyopathies. Chronicle of the World Health Organization, $21,407$.

(I968). Idiopathic cardiomegaly. Account prepared by Fejfar, Z. Bulletin of the World Health Organization, 38, 979. 